\title{
Shared Decision-Making in Breast Reconstruction for Breast Cancer Patients: A Scoping Review
}

\author{
Xuejing $\mathrm{Li}^{\mathrm{I}-3, *}$ \\ Meiqi Meng $\mathbb{D}^{1-3, *}$ \\ Junqiang Zhao $\mathbb{I D}^{4,5}$ \\ Xiaoyan Zhang ${ }^{1-3}$ \\ Dan Yang $\mathbb{D}^{1-3}$ \\ Jiaxin Fang (D) ${ }^{1-3}$ \\ Junxin Wang ${ }^{1-3}$ \\ Liu $\mathrm{Han}^{6}$ \\ Yufang $\mathrm{HaO}$ (I) $^{1-3}$
}

'School of Nursing, Beijing University of Chinese Medicine, Beijing, People's

Republic of China; ${ }^{2}$ Beijing University of Chinese Medicine Collaborating Center of Joanna Briggs Institute, Beijing, People's Republic of China; ${ }^{3}$ Beijing University of Chinese Medicine Best Practice Spotlight Organization, Beijing, People's Republic of China; ${ }^{4}$ School of Nursing, University of Ottawa, Ottawa, Ontario, Canada;

${ }^{5}$ Center for Research on Health and Nursing, University of Ottawa, Ottawa, Ontario, Canada; ${ }^{6}$ Beijing University of Chinese Medicine Third Affiliated Hospital, Beijing, People's Republic of China

*These authors contributed equally to this work

Correspondence: Yufang Hao

Liangxiang High Education Park, Fangshan

District, Beijing, 102488, People's

Republic of China

Tel +86-I3552850210

Email bucmnursing@163.com
Abstract: For most breast cancer (BC) patients who have undergone a mastectomy, the decision whether to proceed with breast reconstruction (BR) is complicated and requires deliberation. Shared decision-making (SDM) helps to address those needs and promote informed value-based decisions. However, little is known about the SDM status for BR in BC patients. This scoping review describes: 1) basic characteristics of studies on BR SDM in BC patients; 2) factors influencing BR SDM in BC patients; 3) experience and perception of BR SDM in BC patients; and 4) outcome measures reported. This review was performed in accordance with the Arksey and O'Malley methodology. A total of 5 English and 4 Chinese databases were searched, as well as different sources from grey literature. The data extraction form was developed by referring to the objectives and the Ottawa Decision Support Framework (ODSF). Data was analyzed using thematic analysis, framework analysis and descriptive statistics, with findings presented in the tables and diagrams. A total of 1481 records were retrieved and 42 of these included after screening. In $21(21 / 42,50 \%)$ of the studies, patient decision aids (PDAs) were utilized, and in $17(17 / 42,40.48 \%)$ of the studies, the factors influencing the implementation of SDM were explored. Of these 17 studies, the factors influencing the implementation of SDM were categorized into the following: the patient level $(17 / 17,100 \%)$, the healthcare level $(2 / 17,11.76 \%)$ and the organizational and system level $(7 / 17,41.18 \%)$. A total of $8(19.05 \%)$ of the 42 studies focused on patients' experiences and perceptions of SDM, and all studies used qualitative research methods. Of these 8 studies, a total of $7(7 / 8,87.50 \%)$ focused on patients' experiences of SDM participation, and $4(4 / 8,50.00 \%)$ focused on patients' perceptions of SDM. A total of 24 studies $(24 / 42,57.14 \%)$ involved quantitative outcome measures, where 49 items were divided into three classifications according to the outcomes of ODSF: the quality of the decision $(17 / 24,70.83 \%)$, the quality of the decision-making process (20/24, 83.33\%), and impact (13/24, 54.17\%). Although researchers have paid less attention to other research points in the field of SDM, compared to the design and application of SDM interventional tools, the research team still presents some equally noteworthy points through scoping review. For instance, the various factors influencing BC patients' participation in SDM for BR (especially at the healthcare provider level and at the organizational system level), patients' experiences and perceptions. Systematic reviews (SRs) should be conducted to quantify the impact of these different factors on BR SDM. Implementation of scientific theories and methods can inform the exploration and integration of these factors.

Keywords: shared decision-making, patients' decisional aids, breast reconstruction, breast cancer, mastectomy, Ottawa Decision Support Framework

\section{Introduction}

Based on the latest data from the new International Agency for Research on Cancer (IARC), female breast cancer (BC) has become one of the most common types of cancer in the world, with 2.3 million cases diagnosed in $2020 .^{1} \mathrm{BC}$ now accounts 
for $11.7 \%$ of all new cancer cases in both sexes. ${ }^{2}$ Yet, the number of women with $\mathrm{BC}$ who had a 5-year survival rate was estimated to be almost 8 million, which is higher than the number of cancer survivors for any other cancer type. ${ }^{3}$

Mastectomy, as a typical surgical treatment approach for $\mathrm{BC}$, has been increasingly performed as a prophylactic measure for women with a genetic predisposition to malignancy. ${ }^{4}$ For women undergoing a mastectomy, their body image will be seriously impacted, which often leads to psychosocial suffering and decreased quality of life. To minimize the adverse impact of mastectomy operations on psychosocial functioning, many patients choose to take breast reconstruction (BR) following mastectomy. ${ }^{5}$ Research has shown that BR can largely improve the patients' mental health, selfesteem, and body image of patients. ${ }^{6-8}$ However, BR also comes with risks that range from minor wound-healing issues to more serious complications, such as venous thromboembolic events or reconstruction failure. 9,10

For women considering BR following mastectomy, the decision-making process is complex and highly dependent on individual patient preferences. ${ }^{11,12}$ The patient must decide whether or not to have the BR, and if BR is chosen, further decisions should also be made on the timing and type of BR (ie, with an implant, autologous tissue or a combination). In their decision-making process, women need to fully understand their current situation and operation-related information and weigh both the benefits and risks of BR to make a personal choice. ${ }^{13}$ Decision-making is further complicated by its urgency that patients only have a short period of time between diagnosis and the surgery to make a final call. During the period, patients commonly feel distressed and anxious, ${ }^{14-16}$ which potentially limits their cognitive functioning and decision-making skills. ${ }^{17}$ Due to the differences in the patients' decision-making process, the patients' reported outcomes for BR were also very diverse.

A comprehensive review ${ }^{18}$ published in 2017 showed that positive aesthetic outcomes widely varied in patients with prosthetic reconstruction, ranging from $36 \%$ to $100 \%$. Positive aesthetic outcomes following autologous reconstruction ranged from $70 \%$ to $90 \%$, satisfaction rates ranged from $41 \%$ to $90 \%$ following prosthetic reconstruction and from $74 \%$ to $75 \%$ following autologous reconstruction. The range of satisfaction with operation outcome was $63.8 \%$ to $70.2 \%$. Given the vulnerable psychological state of this patient population, shared decision-making (SDM) is vital for patients to clarify their preferences before BR surgery, to make the most suitable decision for their individual situation. In addition, SDM can help patients understand the information around $\mathrm{BR}$, in order to rationalize their expectation of surgical outcomes, therefore improving their satisfaction with the operation. Therefore, SDM has been found to be preferable by both patients and surgeons, often correlating with improved surgical outcomes. ${ }^{19}$

SDM is a collaborative model of decision-making that allows patients and clinicians to mutually agree on treatment based on their values and preferences. ${ }^{20-23}$ The conceptual framework of internalizing and realizing a patient's system of decision-making underlies SDM, ${ }^{20,21}$ which has been found to prevent indiscriminate medical interventions, provide a means for patients to determine value-based health outcomes (particularly when multiple options exist), and prevent variation in care paradigms across hospitals. ${ }^{22,23}$ Such outcomes have facilitated the emergence of SDM as an essential component of patient-centered care.

Therefore, the guidelines for BR issued by several national medical institutions have emphasized explicitly that "the decision for BR needs to be made by SDM way, with full consideration of the patient's values and wishes."24-27 One of the guidelines, published jointly by the United States and Canada, states,

presently, based on the evidence reported here, the Work Group recommends that surgeons contemplating BR on their next patient consider the following: the patient's preferences and risk factors, the setting in which the surgeon works (academic versus community practice), resources available, the evidence shown in this guideline. $^{24}$

A Japanese guideline states,

as a decision-making tool for the understanding and treatment of BC, these guidelines will help surgical oncologists, medical staff, and patients, along with their family members to make decision together. ${ }^{25}$

A Dutch clinical decision support system incorporates the recommendations of the European Society of BC Specialists (EUSOMA),

each patient has to be fully informed about each step in the diagnostic and therapeutic pathway and must be given adequate time to consider the alternatives and make an informed decision. ${ }^{26,27}$

However, the guidelines did not set the process and methodologies for SDM, nor did they recommend tools to assist 
patients in SDM. Therefore, there is still a need for learning how best to implement SDM, which is proposed to be done by analyzing the results of studies focused on patient outcomes using SDM.

A systematic search was performed, which identified three systematic reviews (SRs) related to SDM for BR in BC patients. Eventually included were 2 SRs. One detailed SDM intervention tools for patients, and the other on decision-making for BR in older BC patients. The SR on decision-making in older $\mathrm{BC}$ patients included only 1 study on $\mathrm{SDM},{ }^{28}$ where 8 controlled trials about the interventions to support patient decision-making on BR were included (2018). Of the 8 studies, 4 interventions were interactive computer-based programs, 2 were booklets, 1 consisted of educational group intervention, and lastly a printed decision aid. ${ }^{12}$ The result demonstrated a reduction in conflict and regret regarding decision-making, and a improvements in patient satisfaction. The more recent SR (2019) included 17 randomized controlled trials (RCTs), where it was revealed that patient decision aids (PDAs) can improve the quality of BR decision-making, by increasing the knowledge and hence decreasing decisional conflict for $\mathrm{BC}$ patients. ${ }^{11}$

Such results confirmed that SDM is useful for BC patients when facing decisions about BR. But SDM is a broader concept, not limited to the development and implementation of PDAs. For example, the reasons behind the fact that SDM is still not widely used in clinical practice is the lack of knowledge around SDM among plastic surgeons, the high cost of developing and applying PDAs, and that patients are not clear about their roles in the SDM process. These barriers do not only relate to PDAs but the broader concept of SDM. ${ }^{11,29-31}$

Currently, the development of SDM in BR for BC patients has not been systematically and fully explored. Therefore, the aim of this research is to provide an overview of developments in SDM for BC patients when facing decisions specifically around BR surgery. A scoping review was chosen over a full SR to limit research, enabling us to identify the main areas relating to the influencing factors, experience, perception and outcome indicators of SDM in BR. As opposed to providing an overview of all available evidence on SDM for BC patients making decisions around BR. After conducting this scoping review, it is believed this will give us better insight into BR SDM knowledge gaps, which will help us to narrow our focus when conducting a SR as a follow-up study. $^{32,33}$

\section{Materials and Methods}

The scoping review was conducted in accordance with the methodology proposed by Arksey and O'Malley. ${ }^{34}$ It included five steps: (1) identifying the research question, (2) identifying relevant studies, (3) selecting eligible studies, (4) charting the data, and (5) collating, summarizing and reporting the results. A scoping review methodology is appropriate in our study in that it can systematically map evidence on a specific subject matter. ${ }^{34}$ The findings of the present study are reported using the Preferred Reporting Items for SR and Meta-Analysis extension for Scoping Reviews (PRISMA-ScR) reporting guidelines. ${ }^{35}$ (Appendix A). The protocol has been registered in the Open Science Framework (https://osf.io/) (Registered from osf.io/7am3r, Registration DOI 10.17605/OSF.IO/ 8E7Q3). ${ }^{36}$

\section{Stage One: Identifying the Questions}

The aim of the present study is to describe the current research on SDM regarding BR in BC patients. Four research questions were formulated based on the research objectives: 1) What were the characteristics of studies on the SDM of BR in BC patients? 2) What were the influencing factors of BR SDM? 3) What experiences and perceptions related to patient BR SDM have been reported? 4) What SDM outcomes related to BR have been reported?

\section{Stage Two: Identifying Relevant Sources}

A search strategy was developed with the support of a research librarian. The initial search was performed in the databases CINAHL and MEDLINE. This was followed by an analysis of the text words in the title and abstract of retrieved papers, and of the index terms which informed the key terms to be used in next step. All identified keywords and index terms were used to search across all included databases and other websites. The final search was conducted in five English databases: PubMed, CINAHL, EMBASE, Cochrane Library, and PsycINFO, as well as four Chinese databases, that essentially cover all the literature published in Chinese journals: CNKI, WANFANG, VIP and SINOMED. All databases were searched from their inception to September 2020. Grey literature was searched using Google Scholar, professional society's websites, as well as clinical trials registries (Clinical Trial.gov, World Health Organization International Clinical Trials Registry Platform). The final search strategy used for PubMed is included in Appendix $\mathrm{B}$ as an example. 


\section{Stage Three: Study Selection}

Inclusion criteria was based on clearly identifiable populations, concepts and contexts (PCC). ${ }^{37}$ Table 1 illustrates how the PCC acronym was applied. In addition to PCC, we also limited the study design and language in the inclusion criteria. Study selection was performed in several steps. First, after deduplication, review authors (YD and MMQ) double-screened all titles and abstracts in duplicate with the use of NoteExpress 3.2.0 document management software, excluding all studies that were clearly irrelevant and moving studies marked as "unsure" forward to the next stage. The other review author (ZJQ) screened all the "unsure" studies through title/ and abstract to make a final decision. After this, reviewers (FJX and LXJ) double-screened the full text for all studies that were included at the screening stage. In case of any discrepancies, the two review authors who had screened the study in question discussed it further, where necessary including a third review author (HL) in further discussions to achieve a consensus.

For both the title/abstract and full text screening stages, we developed screening guidance forms to ensure that all review authors screened similarly and consistently. All review authors screened $10 \%$ of the search results and discussed discrepancies before starting to screen titles and abstracts. After having screened approximately 150 titles and abstracts, and approximately 20 full texts, inconsistencies and challenges encountered within the review team were discussed. The screening guidance was continually updated and all uncertainties in screening were collected and clarified on a rolling basis. These were discussed in regular online meetings to ensure consistency in screening across multiple review authors.

\section{Stage Four: Extraction and Charting of Data}

There are existing frameworks for guiding the implementation of SDM, such as the Ottawa Decision Support Framework (ODSF) Model. ${ }^{38}$ Over 20 years ago, the ODSF was developed to support researchers and practitioners in gauging people's decisional needs, by helping to provide support and evaluate potential outcomes. ${ }^{38}$ As most medical decisionrelated outcome indicators can be classified into the construct of the ODSF framework, ODSF was employed as the framework to guide the extraction and analysis of the outcome indicators section of this study. As such, based on the ODSF framework and the research aims, the main content extracted in this study can be divided into the following four main categories: general information, factors influencing BR SDM, the process of SDM, and outcomes.

The review team pilot-tested the extraction form (Appendix C) on 5 studies (MMQ and FJX) and subsequently revised it. One review author (LXJ) extracted and charted all study characteristics and data into the categories of the data extraction form in Microsoft Excel (Microsoft Corporation 2018). One experienced review author (ZJQ) then reviewed all extracted data.

\section{Stage Five: Collation, Summary and Reporting of the Results}

This stage involved collating, summarizing and reporting the results of the selected evidence, which was undertaken by the whole research team in an iterative process, until consensus on the thematic results and implications of the scoping review were agreed. Two main strategies were used to analyze the data in this study: 1) descriptive number statistics for general information about the included literature and 2) qualitative

Table I Eligibility Criteria

\begin{tabular}{|c|c|}
\hline Population & $\begin{array}{l}\text { Studies involving BC patients who experienced or about to undergo mastectomy and facing the decision to proceed with BR were } \\
\text { considered in the review, with no restrictions on age or region. }\end{array}$ \\
\hline Concept & $\begin{array}{l}\text { Any studies on SDM in BR for BC patients. Studies including any intervention supporting SDM between BC patients and healthcare } \\
\text { professionals were considered in the review (for example, PDAs, educational programmes for patients or healthcare professionals, } \\
\text { prognostic algorithms and peer support programmes). As well as any research regarding the decisional needs, decisional outcomes or } \\
\text { decisional influencing factors of BR in BC patients. }\end{array}$ \\
\hline Context & Studies conducted in a broad geographical context or therapeutic setting were considered in the review, with no limitations \\
\hline $\begin{array}{l}\text { Study } \\
\text { design }\end{array}$ & $\begin{array}{l}\text { Cross-sectional study, qualitative study, mixed-method study, cohort study, case-control study, case study and RCT. (Excluded } \\
\text { research types: review, opinion, news, comment, and research that can only obtain abstract) }\end{array}$ \\
\hline Language & There were no restrictions on the language included in the literature in this study. \\
\hline
\end{tabular}


thematic analysis. ${ }^{39}$ Before thematic analysis, we started with a classification by one researcher (LXJ), based on the study's objectives (such as exploring SDM influencing factors, SDM experiences and perceptions, SDM intervention outcomes, etc.). The framework analysis method was applied to the outcome section, primarily because the outcome section was extracted based on the ODSF construct. Then, a qualitative thematic analysis was conducted for the other categories. Firstly, the extracted content was familiarized with researchers through repeated reading, then subsequently analyzing the data by assigning primary and secondary topics to the data through coding. Finally, a descriptive analysis of all primary and secondary themes was performed (number and percentage of literature). The lead author (LXJ) wrote the scoping analysis, which was then checked independently by three collaborators (MMQ, YD, and ZJQ), who fed back their comments. Any disagreements were discussed and resolved.

\section{Ethical Considerations}

The present investigation relied on secondary data analysis, which is available in the database of scientific literature and, therefore, did not require submission to the Research Ethics Committee.

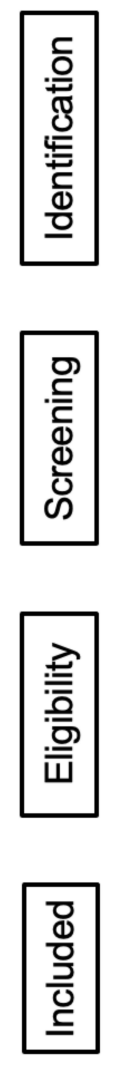
WANFANG=1, VIP=1, SINOMED=2]

\section{Results}

A total of 1481 records were retrieved and 42 were finally included after screening. Figure 1 illustrates the searching and selection process. A list of included studies is shown in Appendix D. PDAs were utilised in $21(21 / 42,50 \%)$ of the papers. Seventeen studies $(17 / 42,40.48 \%)$ were concerned with the factors influencing the implementation of SDM. The areas of concern in these 17 studies were categorized into: the patient level $(17 / 17,100 \%)$, the healthcare level $(2 / 17,11.76 \%)$ and the organizational and system level $(7 / 17,41.18 \%)$. A total of $8(8 / 42$, $19.05 \%$ ) of the studies focused on patients' experiences and perceptions of SDM, and all 8 used qualitative research methods. Of these 8,7 studies (7/8, 87.50\%) focused on patients' experiences of SDM participation and $4(4 / 8,50.00 \%)$ focused on patients' perceptions of SDM. Out of the total 42 included studies, 24 (24/42, $57.14 \%$ ) involved quantitative outcome measures with 49 items. These items were divided into three classifications, by the first coding according to the outcomes of the ODSF model, including: the quality of the decision $(17 / 24$, $70.83 \%)$, the quality of the decision-making process $(20 /$ $24,83.33 \%)$, and impact (13/24, 54.17\%).

[Google Scholar $=1864$, professional society's websites $=0$, Clinical Trial.gov $=5$, WHO International Clinical Trials Registry Platform=5]

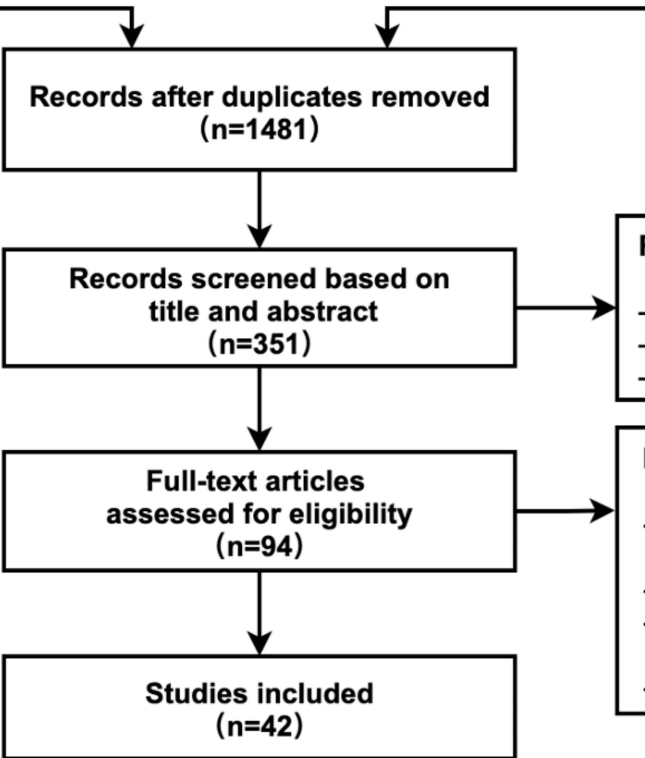

Records excluded by abstract ( $n=257)$

-Congress abstract

-Not about breast reconstruction -Not about SDM

Records excluded by full-text $(n=52)$

-Participants are not breast cancer patients $=15$

-Comments $=4$

-SDM only mentioned in

abstract $=26$

-Cannot get full-text=7

Figure I Scoping review flowchart. 


\section{Basic Characteristics of Included Studies}

The basic characteristics of included studies are presented in Table 2 and the respective years of publication in Figure 2. The first study to detail SDM in BR for BC patients was published in 1999. Of the 42 included studies, the largest was a cross-sectional and correlational study that included 2906 patients, with the youngest participant being aged 25 years old and the oldest being 87 years old at the time. As for location of studies, the majority were conducted in America (16/42, 38.10\%), followed by Europe (10/42, 23.81\%), Asia (9/42, 21.43\%), and Australia (7/42, 16.67\%). A total of 29 studies $(69.05 \%)$ reported funding sources.

Table 2 Basic Characteristics of Included Studies

\begin{tabular}{|c|c|c|c|}
\hline General Information About the Literature & Classification & Number & Proportion (\%) \\
\hline \multirow[t]{2}{*}{ Funding Support } & Yes & 29 & 69.05 \\
\hline & No & 13 & 30.95 \\
\hline \multirow[t]{4}{*}{ Location } & Asia & 9 & 21.43 \\
\hline & Europe & 10 & 23.81 \\
\hline & America & 16 & 38.10 \\
\hline & Australia & 7 & 16.67 \\
\hline \multirow[t]{5}{*}{ Research method } & Cross-sectional and correlational approach & 12 & 28.57 \\
\hline & Randomised controlled trial & 9 & 21.43 \\
\hline & Interviews & 10 & 23.81 \\
\hline & Mixed-methods & 8 & 19.05 \\
\hline & Cohort study & 3 & 7.14 \\
\hline \multirow[t]{5}{*}{ Patients' cancer stage } & Risk of BC & 3 & 7.14 \\
\hline & BC newly diagnosed & 8 & 19.05 \\
\hline & $B C$ is diagnosed and will be resected soon & II & 26.19 \\
\hline & Undergone mastectomy for $\mathrm{BC}$ & 11 & 26.19 \\
\hline & Undergone $B R$ after $B C$ surgery & 7 & 16.67 \\
\hline \multirow[t]{5}{*}{ SDM settings } & Hospital & 10 & 23.81 \\
\hline & Healthcare centre & 2 & 4.76 \\
\hline & Telephone & I & 2.38 \\
\hline & Online & 6 & 14.29 \\
\hline & Patients preferred setting & 4 & 9.52 \\
\hline \multirow[t]{4}{*}{ Framework } & Decision Support Framework (DSF) & 6 & 14.29 \\
\hline & Implementation research framework & I & 2.38 \\
\hline & Psychological theoretical models & 2 & 4.76 \\
\hline & Jain and Mann' Conflict Model & I & 2.38 \\
\hline \multirow[t]{9}{*}{ Implementer } & Plastic surgeon & 14 & 33.33 \\
\hline & Surgical oncologist & 14 & 33.33 \\
\hline & Nurse specialist & 8 & 19.05 \\
\hline & Social worker & 2 & 4.76 \\
\hline & Clinical psychologist & 3 & 7.14 \\
\hline & Medical oncologist & I & 2.38 \\
\hline & Physician & 2 & 4.76 \\
\hline & Researcher & 3 & 7.14 \\
\hline & Healthcare professional & 3 & 7.14 \\
\hline \multirow[t]{4}{*}{ Decision issues } & All three of the following are included & 7 & 16.67 \\
\hline & (I) Should I have BR? & 4 & 9.52 \\
\hline & (2) Should I start immediately or delay? & 10 & 23.81 \\
\hline & (3) Should I use a flap of my own tissue or an implant? & 5 & 11.90 \\
\hline Tools & PDAs & 21 & 50.00 \\
\hline
\end{tabular}




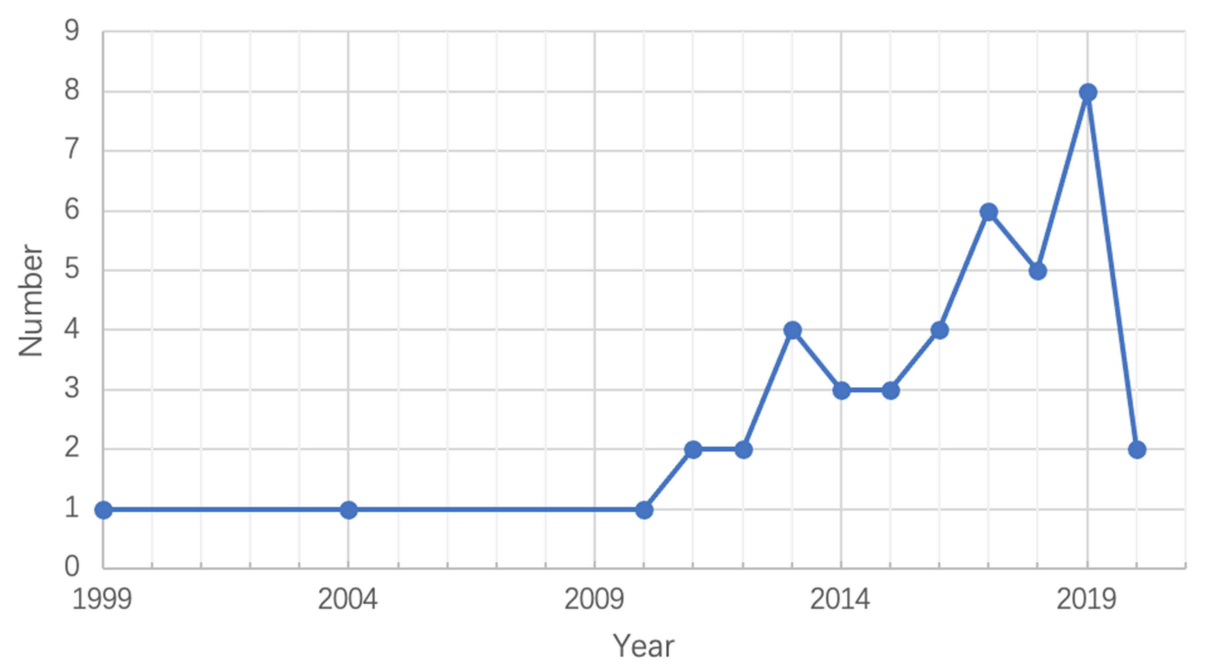

Figure 2 Literature publication over time.

The cancer stage of patients varied from study to study, but situations where SDM was used in included the following: when a BC diagnosis was received and due to be resected soon $(11 / 42,26.19 \%)$, when a patient was about to undergo mastectomy for BC $(11 / 42,26.19 \%)$, when BC was newly diagnosed $(8 / 42,26.19 \%)$ and after BC surgery $(7 / 42,16.67 \%)$. The SDM settings of the studies predominately include hospital $(10 / 42,23.81 \%)$, online $(6 / 42,14.29 \%)$ and patients preferred setting $(4 / 42,9.52 \%)$. In terms of SDM implementers, the most common implementers were plastic surgeons (14/42, $33.33 \%$ ) and surgical oncologist (14/42, 33.33\%), followed by nurse specialists $(8 / 42,19.05 \%)$. Only 10 studies $(10 / 42$, $23.81 \%$ ) mentioned the use of appropriate frameworks for research, of which the most commonly used was the Decision Support Framework (DSF) (6/42, 14.29\%).

PDAs were utilized in 21 papers $(21 / 42,50.00 \%)$. These PDAs included the Decision Manual, BREAST Choice Tool, Pink Journey, Breast Reconstruction Decision Aid (BRECONDA), Patients' Expectations and Goals: Assisting Shared Understanding of Surgery (PEGASUS) Coach, BRAID, Patient Decision Aid Video and Workbook, and post-mastectomy breast reconstruction (PMBR). Other tools primarily included health education manuals and health education videos that are not clearly defined as PDAs. BRECONDA, ${ }^{40-43}$ PEGASUS Coach ${ }^{44-46}$ and BRAID $^{47}$ are known to be the most widely employed PDAs.

\section{Factors Influencing BR SDM in BC Patients} A total of $17(17 / 42,40.48 \%)^{42,48-63}$ of the 42 included studies focused on factors influencing the implementation of SDM. The factors were categorized into the following: patient level, ${ }^{42,48-63}$ the healthcare level, ${ }^{42,63}$ and the organizational and system level. ${ }^{39,42,53,55,57,58,63}$

On the patient level, all 17 focused on the measurement of patient-level influences $(17 / 17,100 \%),{ }^{42,48-63} 11$ (11/ $17,64.71 \%$ ) focused on patient socio-demographic information, ${ }^{5-58,63} 10(10 / 17,58.82 \%)$ focused on patient disease-related information, ${ }^{48,50-55,58-60} \quad 15 \quad(15 / 17$, $88.24 \%$ ) focused on patient information needs, ${ }^{42,48-55,57-}$ 59,61-63 and $14(14 / 17,82.35 \%)^{48,50,52-60,62,64,65}$ addressed the psychological needs of patients.

On the healthcare level, a total of 2 studies $(2 / 17$, $11.76 \%$ ) focused on the measurement of influencing factors, the formation of multidisciplinary healthcare teams, healthcare professionals' attitudes towards SDM, and healthcare professionals' level of SDMrelated knowledge, ${ }^{42,63}$ and $1(1 / 17,5.88 \%)$ concerned with healthcare workers' perceptions of stress regarding new knowledge and processes (such as SDM). ${ }^{63}$

On the organizational and system level, a total of 7 studies $(7 / 17,41.18 \%)$ focused on the evaluation of organizational environmental factors, ${ }^{42,49,53,55,57,58,63} 4(4 / 17$, $23.53 \%$ ) evaluated the hardware configuration of the hospital, ${ }^{49,53,55,57} 3(3 / 17,17.65 \%)$ evaluated the doctorpatient relationship in a broader context, ${ }^{42,55,63} 2(2 / 17$, $11.76 \%$ ) assessed the availability of evidence-based resources ${ }^{58,63} 1(1 / 17,5.88 \%)$ assessed SDM-related training, ${ }^{63}$ and $1(1 / 17,5.88 \%)$ assessed the current health education resources. ${ }^{58}$ Specific results are exhibited in Table 3. 
Table 3 Classification of Factors Influencing BR SDM in BC Patients (17 of 42 Studies Reported)

\begin{tabular}{|c|c|c|}
\hline Primary Themes & Secondary Themes & $\begin{array}{l}\text { No. of } \\
\text { Studies } \\
\text { (\%) }\end{array}$ \\
\hline \multirow[t]{4}{*}{ Patient level ${ }^{37-53}(17 / 17,100 \%)$} & $\begin{array}{l}\text { Sociodemographic data }{ }^{37-43,45-47,53} \\
\text { Age }^{37-41} \\
\text { Income }^{42,43} \\
\text { BMI }^{41} \\
\text { Race }^{46,47} \\
\text { Education }^{38,39,45} \\
\text { Work and hobbies } \\
\text { Private insurance } \\
\text { Cognitive level } \\
\text { C6,53 }\end{array}$ & II (64.7I\%) \\
\hline & $\begin{array}{l}\text { Disease-related data }{ }^{37,39-44,47-49} \\
\text { Cancer stage }^{37,40-44,47,49} \\
\text { Complications }^{47-49} \\
\text { Pain tolerance } \\
\text { Anatomical typing of tumor } \\
\text { Is an anterior lymph node biopsy required } \\
\text { Whether to undergo a bilateral mastectomy }{ }^{30,44,46,46,47} \\
\text { Adjunct treatment regimen } \\
\text { 37,40,41,44,47 }\end{array}$ & $10(58.82 \%)$ \\
\hline & $\begin{array}{l}\text { Information needs }{ }^{37-44,46-48,50-53} \\
\text { The applicability of BR to the patient's own condition }{ }^{37,39,40,42,43,46-48,51-53} \\
\text { BR timing }{ }^{38-44,47,48,50,52} \\
\text { Source of BR fillers } \\
\text { Surgical method for BR } \mathrm{BR}^{37-39,44,47,50,52,53} \\
\text { Relationship between surgical treatment and reconstruction of BC } \\
\text { Potential risks or complications }{ }^{37-44,46-48,50,52,53} \\
\text { Post-operative breast appearance }{ }^{37-39,41,42,44,46,47,53} \\
\text { Operation cost }{ }^{37,40,42-44,46-48,50-53}\end{array}$ & $15(88.24 \%)$ \\
\hline & 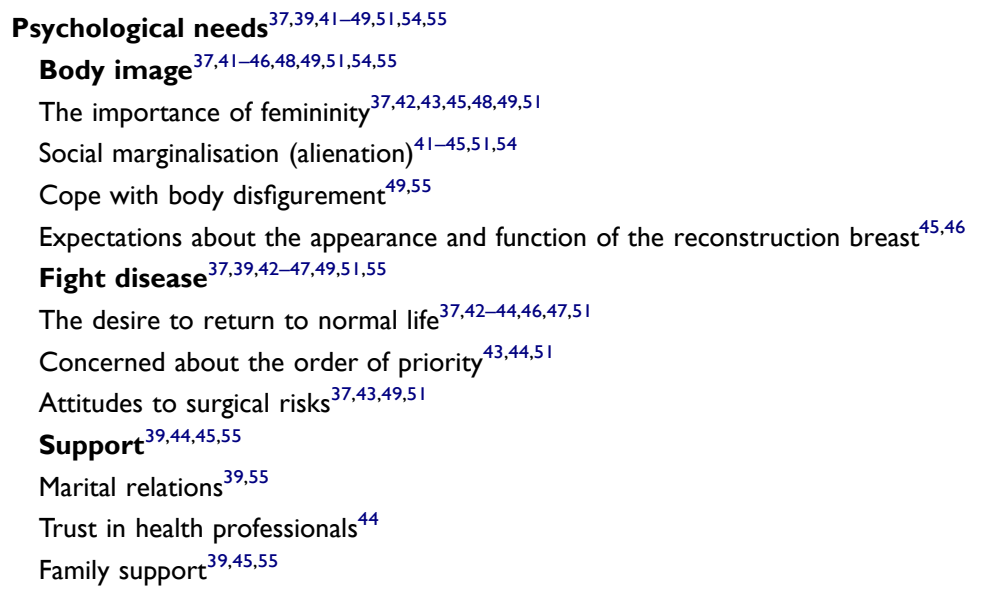 & $14(82.35 \%)$ \\
\hline \multirow[t]{4}{*}{ Healthcare level ${ }^{52,53}(2 / 17,11.76 \%)$} & Establishment of a multidisciplinary medical team ${ }^{52,53}$ & $2(11.76 \%)$ \\
\hline & Stress perception ${ }^{53}$ & I (5.88\%) \\
\hline & Attitudes $^{52,53}$ & $2(\mathrm{I} I .76 \%)$ \\
\hline & Knowledge of SDM ${ }^{52,53}$ & 2 (II.76\%) \\
\hline
\end{tabular}

(Continued) 
Table 3 (Continued).

\begin{tabular}{|c|c|c|}
\hline Primary Themes & Secondary Themes & $\begin{array}{l}\text { No. of } \\
\text { Studies } \\
\text { (\%) }\end{array}$ \\
\hline \multirow{5}{*}{$\begin{array}{l}\text { Organizational system } \\
\text { level } \\
38,42,44,46,47,52,53 \\
(7 / 17,41.18 \%)\end{array}$} & Hospital hardware configuration ${ }^{38,42,44,46}$ & $4(23.53 \%)$ \\
\hline & The doctor-patient relationship in a broader context ${ }^{44,52,53}$ & $3(17.65 \%)$ \\
\hline & Accessibility of evidence-based resources ${ }^{47,53}$ & $2(11.76 \%)$ \\
\hline & SDM-related training ${ }^{53}$ & I (5.88\%) \\
\hline & Current health education resources ${ }^{47}$ & I (5.88\%) \\
\hline
\end{tabular}

\section{Experience and Perception of BR SDM in BC Patients}

Of the 42 included studies, 8 (8/42, 19.05\%)$40,42,46,58,63,67,68,70$ focused on patients' experiences and perceptions of SDM, all of which used qualitative or mixed research methods. Of these 8,7 studies $(7 / 8$, $87.50 \%)^{40,42,46,63,67,68,70}$ focused on patients' experiences of SDM participation, with $5(5 / 8,62.50 \%)^{40,42,67,68,70}$ focused on patients' attitudes towards SDM and $5(5 / 8$, $62.50 \%)^{40,42,46,63,70}$ focused on the impact of SDM on patients. A total of 4 studies $(4 / 8,50.00 \%)^{42,46,58,68}$ focused on patients' perceptions of SDM and how SDM was conducted, and $2(2 / 8,25.00 \%)^{42,58}$ involved patients' perceptions of the content of the interventional tools. Specific results are exhibited in Table 4.

\section{The Outcomes of Participation in SDM of BC Patients Undergoing BR}

Of the 42 studies included, 24 (24/42, 57.14\%) involved quantitative outcome measures, ${ }^{40,43,46,47,49,52,57,61,62,64,66,67,69-80}$ totaling 49 quantitative outcome indicators. The first coding was performed according to the outcomes of ODSF. ${ }^{38}$ As a result, 49 quantitative outcome measures were divided into three first-level classifications: the quality of the decision, the quality of the decision-making process, and impact. On this basis, manual classification was performed according to the

Table 4 Experience and Perception of BR SDM in BC Patients (8 of 42 Studies Reported)

\begin{tabular}{|c|c|c|}
\hline Primary Themes & Secondary Themes & $\begin{array}{l}\text { No. of Studies } \\
\text { (\%) }\end{array}$ \\
\hline \multirow[t]{2}{*}{$\begin{array}{l}\text { Patients' Experience of the SDM Process } 29,35,52,53,57,58,60 \\
87.50 \%)\end{array}$} & $\begin{array}{l}\text { Patients' Attitude }{ }^{29,52,57,58,60} \\
\text { Clarity, visualisation and effectiveness of } \\
\text { information } \\
\text { Patients' acceptance and satisfaction }{ }^{60}\end{array}$ & $5(62.50 \%)$ \\
\hline & $\begin{array}{l}\text { Impact on patients }{ }^{29,35,52,53,60} \\
\text { Medical trust }{ }^{52,53} \\
\text { Patient Self-Confidence }{ }^{5-, 29-, 35-, 53-, 60} \\
\text { Patient involvement in decision making }\end{array}$ & $5(62.50 \%)$ \\
\hline \multirow[t]{2}{*}{ Patients' Perception on the SDM Process ${ }^{35,47,52,58}(4 / 8,50.00 \%)$} & $\begin{array}{l}\text { The form of SDM }{ }^{35,47,52,58} \\
\text { Specificity and individualisation of the tools }{ }^{47,52} \\
\text { Individual expectations and expression of needs }{ }^{35,47,58} \\
\text { Individual roles and tasks }\end{array}$ & $4(50.00 \%)$ \\
\hline & $\begin{array}{l}\text { Contents of the tool }{ }^{47,52} \\
\text { Access to tools and instructions for use } \\
\text { Comparative information for decision making } \\
\text { Previous patient experience } \\
\text { 47,52 }\end{array}$ & $2(25.00 \%)$ \\
\hline
\end{tabular}


specific content under the corresponding first-level category, coded into 9 second-level classifications. Among the 49 outcome indicators involved, the most often outcomes were concerning decision conflict $(12 / 49,24.49 \%)$, knowledge (12/49, $24.49 \%$ ), and satisfacthion ( $7 / 49,14.29 \%)$.

Of those 24 studies involving quantitative outcome measures, $17(17 / 24,70.83 \%)$ involved a total of 18 outcome measures related to the quality of the decision, which was defined by informed indicators (essential knowledge, realistic outcome expectations) and values-based indicators (choice matches features that matter most). ${ }^{42,46,47,49,52,62,64,67,70,72-78,80}$ These included patient knowledge $(12 / 24,50.00 \%)$, patient preference $(12 / 24,50.00 \%)$, and satisfaction $(7 / 24$, $29.17 \%$ ). Of these, the most commonly used measure for the evaluation of patient knowledge was the knowledge of a BR study-specific questionnaire.

As well, 20 studies $(20 / 24,83.33 \%)$ reported the change in quality of the decision-making process, which primarily involved a reduction of decision needs, a reduction in the proportion of patients who were undecided, and a reduction in self-image perception. These were reported as a perceived involvement in the decision-making process $(6 / 24,25.00 \%)$, preparedness for decision-making $(19 / 24,79.17 \%)$, and other $(2 / 24, \quad 8.33 \%) .{ }^{40,43,46,47,57,61,62,64,66,67,69-76,79,80}$ The most commonly used evaluation of the former two used subscales from the Modified-Perceived Involvement in Care Scale (M-PICS) and Decision Conflict Scale (DCS), respectively. The impact on implementation and continuance of the chosen option was included by 13 studies $(13 / 24,54.17 \%)$,43,46,49,61,66,71-73,75-79 where health-related outcomes were the commonly evaluated and other outcome measures included final treatment decision and appropriate use/costs of health services. The indicators in the included studies are detailed in Table 5.

\section{Discussion}

\section{Research and Development Status of SDM Related to BR}

As the theory and tools related to SDM have developed, research around the relationship between $\mathrm{BC}$ and BR has gradually increased in correlation. Furthermore, the related technology for BR is constantly advancing and has become more widely accepted by patients. The first PDAs related study on BR was conducted in 2008. In this study, an "education aid" was formulated on the computer network and video, which can be regarded as the basis of decision-making aids for patients with $\mathrm{BR} .{ }^{81}$ Nearly half of the studies included originated either from Canada or the United States, which is significant as Canada and the United States are the world's leading researchers of SDM. ${ }^{82}$ To bring this into perspective, Ottawa Hospital Research Institute in Canada (www.deci sionaid.ohri.ca/index.html), EBSCO information services in the United States (www.ebsco.com/), and Mayo Clinic SDM National Resource Centre (www.shareddecisions. mayoclinic.org/) all established websites related to PDAs, which have been widely spread all over the world.

This review showed that in spite of PDAs being widely used in the field of SDM for BR patients, and improvements in the quality of PDAs (such as BRECOND $^{40,41}$ and PEGASUS, ${ }^{44,45}$ ), many studies involving PDAs that have been constructed autonomously have not been professionally evaluated for quality. ${ }^{42}$ Additionally, this review showed that the dissemination and utilization of high-quality PDAs may be facing serious challenges. The function and purpose of the PDAs used during SDM for BR patients in question are similar, such as it aids patients and health professionals in clarifying each woman's motivations for $\mathrm{BR}^{83,84}$ However, this review did not identify any PDAs that were derived from the indigenous transformation of existing PDAs. Therefore, it is necessary for us to uncover the barriers and facilitators to the localization of PDAs, and explore the methodological processes for the localization of PDAs.

\section{Factors Influencing BR SDM in BC Patients}

A total of 17 studies measured factors influencing SDM implementation at the patient level, ${ }^{42,48-63}$ the healthcare level, ${ }^{42,63}$ and the organizational system level. ${ }^{42,49,53,56-}$ 58,63 Most studies measured patients' sociodemographic information, ${ }^{48-54,56-58,63}$ with age ${ }^{48-52}$ and $\mathrm{BMI}^{52}$ providing some indication of each patients' physical and cognitive status. It has been shown that older patients will be less demanding regarding their image, ${ }^{85}$ and may also have varying degrees of cognitive decline, therefore hindering their ability to understand and receive information related to $\mathrm{BR}{ }^{86}$ This may explain why age can affect patients' SDM participation. Income, ${ }^{53,54}$ race, ${ }^{57,58}$ education, ${ }^{49,50,56}$ work, ${ }^{42}$ hobbies, ${ }^{42}$ private insurance, ${ }^{46,49}$ 
Table 5 Quantitative Outcome Indicators (24 of 42 Studies Reported)

\begin{tabular}{|c|c|c|}
\hline Primary Theme & Quantitative Outcome Indicators & $\begin{array}{l}\text { No. of } \\
\text { studies (n } \\
(\%))\end{array}$ \\
\hline \multirow[t]{3}{*}{$\begin{array}{l}\text { Quality of the } \\
\text { decision }^{35,38,41,42,51,52,54,57,60,62-68,70} \\
(17 / 24,70.83 \%)\end{array}$} & $\begin{array}{l}\text { Patient knowledge }{ }^{38,42,51,57,60,62-67,70} \\
\text { Knowledge of breast reconstruction study-specific questionnaire }{ }^{42,51,57,60,63-67,70} \\
\text { The knowledge subscale of the validated Decision Quality Index (DQI) })^{62} \\
\text { Information on breast surgeons' oncoplastic and reconstructive experience and skills }{ }^{38}\end{array}$ & $12(50.00 \%)$ \\
\hline & $\begin{array}{l}\text { Patient preference }{ }^{35,38,41,42,52,54,57,62,64,65,68,70} \\
\text { Choice regarding breast reconstruction patient-reported questions }{ }^{41,42,54,64,65} \\
\text { Decision Preference and Decision Choice } \\
\text { Patient involvement in decision making Control Preferences Scale } \\
\text { Participants' decision predisposition regarding PDAs }{ }^{70} \\
\text { How certain they felt about that choice } \\
\text { The Personal Decision Worksheet } \\
\text { Decision-Making Values subscale } \\
\text { Reasons to have and not to have breast reconstruction } \\
\text { Breast reconstruction intentions and decisions }{ }^{64} \\
\text { Hereditary risks and the patient's own desire } \\
\text { ICECAP-A capabilities }\end{array}$ & $12(50.00 \%)$ \\
\hline & $\begin{array}{l}\text { Satisfaction } \\
\text { Decision Regret Scale (DRS) }{ }^{32,35,42,50,61,66} \\
\text { Satisfaction with Breast Outcome of the BREAST-Q }{ }^{42} \\
\text { Subscale Satisfaction with Information/Satisfaction with plastic surgeon }{ }^{42} \\
\text { Physical satisfaction }\end{array}$ & 7 (29.17\%) \\
\hline \multirow[t]{3}{*}{$\begin{array}{l}\text { Quality of the decision making } \\
\text { process }^{29,32,35,42,46,50,51,54,56,57,59-} \\
66,69,70(20 / 24,83.33 \%)\end{array}$} & $\begin{array}{l}\text { Perceived involvement in the decision-making process }{ }^{35,42,50,56,62,65} \\
\text { Two subscales from the Modified-Perceived Involvement in Care Scale (M-PICS) } \\
\text { CollaboRATE (a 3-item self-report measure of the patient experience of SDM process) })^{35,62} \\
\text { Involvement in the BR decision-making process scale } \\
\text { Shared Decision Making Questionnaire (SDM-Q-9) } \\
\text { The decision process subscale of the DQI } \\
\text { Three items from the Patient Activation Measure (PAM) }\end{array}$ & $6(25.00 \%)$ \\
\hline & $\begin{array}{l}\text { Preparedness for decision making }{ }^{29,32,35,42,46,51,54,56,57,59-66,69,70} \\
\text { Decision Conflict Scale (DCS) })^{32,35,42,56,59-66} \\
\text { Treatment Implementation and fidelity }{ }^{46,51,54,62,65,66} \\
\text { Feasibility and acceptability Usability: Ottawa Acceptability Scale } \\
\text { Preparation Decision Making (PrepDM) } \\
\text { Preparation for Decision Making Scale }{ }^{42}\end{array}$ & $19(79.17 \%)$ \\
\hline & $\begin{array}{l}\text { Others }^{62,65} \\
\text { Consultation length } \\
\text { Timing of reconstruction } \\
\end{array}$ & $2(8.33 \%)$ \\
\hline
\end{tabular}

and hospital configuration ${ }^{49,53,55,57}$ are also a reflection of the patient's cultural background, social status and personal character. Studies investigating patient involvement in SDM have also confirmed that different literacy levels and social status influence patients' perceptions of diseaserelated information. ${ }^{87}$ Patients with higher literacy and social status tend to be more motivated to participate in SDM. It has also been shown that patients with different personalities have different attitudes towards illness, and that desire to express their values such as patients extrovert personalities are more likely to participate in shared decision-making with healthcare. ${ }^{88}$ 
Table 5 (Continued).

\begin{tabular}{|c|c|c|}
\hline Primary Theme & Quantitative Outcome Indicators & $\begin{array}{l}\text { No. of } \\
\text { studies (n } \\
(\%))\end{array}$ \\
\hline \multirow[t]{3}{*}{$\begin{array}{l}\text { Impact }^{32,35,38,42,50,56,61,62,65-69}(13 / \\
24,54.17 \%)\end{array}$} & $\begin{array}{l}\text { Health-related outcomes }{ }^{32,35,38,42,50,56,61,62,65-69} \\
\text { BREAST-Q reconstruction module } \\
\text { Hospital Anxiety and Depression Scale, HADS }{ }^{61,66,68,69} \\
\text { Health-Related Quality of life EQ5DL } \\
\text { Anxiety STAI-6 (State scale of the StateTrait Anxiety Inventory) } \\
\text { Body image Subscale Body Image of the EORTC QLQ-BR23 } \\
\text { Health outcomes }{ }^{42,65} \\
\text { Breast symptoms Subscale Breast Symptoms of the EORTC QLQ-BR23 } \\
\text { Sexual functioning Subscale Sexual Functioning of the EORTC QLQ-BR23 } \\
\text { Reconstructive possibilities and the experience of participation }\end{array}$ & $13(54.17 \%)$ \\
\hline & $\begin{array}{l}\text { Final treatment decision } \\
\text { Treatment received } \\
\text { T2,65 }\end{array}$ & $2(8.33 \%)$ \\
\hline & $\begin{array}{l}\text { Appropriate use/costs of health services }{ }^{32,35,42,62,68} \\
\text { Cost-effectiveness Use of healthcare services }{ }^{32,42} \\
\text { A selection of questions of the Medical Consumption Questionnaire }{ }^{42} \\
\text { Medical consumption }{ }^{42} \\
\text { Cost per Quality-adjusted Life Year gained based on the EQ5DL scores }{ }^{35} \\
\text { Average cost of implementing PDAs per site } \\
\text { Average cost per patient }{ }^{35,68} \\
\text { Cost per hour of SDM } \\
\text { Time spent using PDAs: through electronic timestamps } \\
{ }^{62}\end{array}$ & $5(20.83 \%)$ \\
\hline
\end{tabular}

In 10 studies disease-related information about patients was recorded, as this information can also indicate the patient's health status. ${ }^{48,50-55,58-60}$ In BR surgery, patients must undergo preoperative preparation, anesthesia, and postoperative care, and even face postoperative complications and secondary surgeries. ${ }^{93}$ As a result, the patient's physical condition must adhere to certain requirements. For example, when the patient's disease is serious and urgent, or when the adjuvant treatment received is already too much for the patient to bear, the patient may choose not to make this decision. ${ }^{94-96}$ The results of a SR of pediatric SDM published in 2019 also clarifies that the characteristics of the parents and child are one of the pediatric SDM barriers. In this particular study, characteristics included sociodemographic information and the health status of both parents and children. ${ }^{89}$

Patients' information needs are the key topic of interest in the current phase of SDM research for BR. SRs of pediatric SDM and oncology addressed barriers to SDM promotion, and showed that availability of clinical and research information, as well as the level of high-quality tailored information given to the patient, are influencing factors of the implementation of SDM in this area. ${ }^{89,90}$ Although the studies took place in different countries, with participant samples who varied in demographics, women experienced the pain of reconstruction and the struggle with recovery in similar ways. Thus, they will have many common needs regarding information required to make a decision around having BR. However, patients in different situations will also have individual information needs, that may not be tested by the questionnaire, suggesting that researchers should also focus on how to measure patients' information needs comprehensively in subsequent studies.

Patients' psychological needs are also often directly related to a patients' values and attitudes, ${ }^{91}$ and NICE guidelines referred to SDM as, "a process whereby patients learn information about decision-making and then clarify their values to make decisions". ${ }^{92}$ In the BC patient population, several studies articulated that patients who decide to have postmastectomy BR assign importance to the decision factors surrounding body image, 
femininity, attractiveness, and sexuality. ${ }^{97}$ The individual's level of significance associated with the breast should be considered in the physician-patient communication regarding BR. $^{98,99}$

At the healthcare level, the areas of concern for BR SDM did not differ significantly from the SRs for pediatric and oncology. The areas focused on time, attitude, cognition, and comfort with new knowledge and work processes. ${ }^{89,90}$ However, it is clear that there is a relatively small accumulation of studies focusing on the measurement of healthcare level influencing factors, and the results from the two current studies included are still not rich enough to support a new SR to generate evidence.

Although some studies report on the evaluation of organizational systems, their focus is still relatively onesided. In 2018, Scholl et al published an item focusing on organizational-system level characteristics that influenced implementation. ${ }^{100}$ Their study categorized the influences of the organizational system as organizational leadership, organizational teamwork, organizational workflows, incentives, and policies and guidelines. It is obvious that, in contrast, there are still many aspects of the BC BR field that have not been attended to, and research should continue to be conducted regarding other areas of research design at the organizational system level.

\section{Experience and Perception of BR SDM in BC Patients}

Patients' experiences of SDM participation included primarily attitudes toward SDM, such as their feelings about the information and acceptability of the tool. ${ }^{40,42,67,68,70}$ This is consistent with SDM research in other fields, where researchers have studied the effectiveness and safety of interventions, and focused on their acceptability, feasibility, and utility in specific disease areas. Issues related to the acceptability of any SDM interventions to patients, and the feasibility of their implementation, were identified in five SRs from different domains. ${ }^{101-105}$ The qualitative research approach allows for a deeper exploration of patients' experiences of SDM, and patients often express their attitudes and their own needs, which can have a positive effect on improving the SDM methodology. ${ }^{106}$ Qualitative studies also often focus on the impact of SDM on patients, ${ }^{40,42,46,63,70}$ which is somewhat intersected with the "outcomes" part of the results. However, though the focus is on the impact of SDM, qualitative studies focus more on the personal narratives of the patients impacted. This results in primarily findings around patients' trust in healthcare, ${ }^{42,63}$ patients' confidence in decision-making, ${ }^{40,42,46,63,70}$ and patients' involvement in the decision-making. ${ }^{63}$ As direct participants in SDM and direct users of decision aids, patients are often able to make suggestions regarding the methods, processes, and tools of SDM from a different perspective, compared to researchers and healthcare professionals. ${ }^{107}$ The International Patient Decision Aids Standards (IPDAS), a set of quality criteria for patient decision support technologies, also suggests that patient decision support technologies should be extensively tested with patients before they are put into use. ${ }^{108}$

\section{The Outcomes of Participation in SDM of BC Patients Undergoing BR}

How to evaluate and analyze the current situation regarding SDM both scientifically and effectively is an important topic explored by scholars. We need to select appropriate and high-quality outcome indicators to measure SDM, which is still challenging today, although considerable research results about SDM have been accumulated. At present, there are few reviews on the outcome measurements of $\mathrm{BC}$ patients participating in SDM, especially when focusing on $\mathrm{BC}$ patients undergoing BR. This field requires researchers to further explore effective outcome indicators, the most effective methods of measuring patients' values and preferences in reconstruction decision-making, to address the methodological challenges related to such measurements. Our review highlights several important points regarding the assessment of outcomes of SDM in BC patients with BR.

First, the results of our study show that among the 49 outcome indicators involved in 24 studies, outcomes were most often concerning decision conflict, knowledge, and satisfaction, which is consistent with previous studies. A scoping review of the literature in 2020 systematically reviewed SDM in surgery and found that the first three indicators most often involved in measuring the outcome of SDM are knowledge, decision conflict and decision satisfaction. ${ }^{109}$ Other outcomes included surgical intervention rate, SDM preference, decision regret, and time required to use SDM. In another SR published in 2019, feasibility and efficiency of decision aids to improve decision-making for postmastectomy BR was investigated. ${ }^{110}$ The self-reported outcome of BR patients using PDAs primarily centered around information satisfaction, 
perceived participation in the decision-making process, and decision conflict. However, the outcome indicators we need to pay attention should not be limited to this.

Second, given the particularity of the surgical site of BR, health-related outcomes in BR SDM differ from most surgical SDM, in that we need to pay more attention to aesthetic effects and body image, in addition to anxiety and depression. When assessing health outcomes associated with SDM, the outcomes have most often been measured via patient self-report. This study shows that among the health-related outcomes closely related to their quality of life, patients with BR SDM pay more attention to the outcome indicators such as body image, and sexual functioning, in addition to anxiety and depression. This was also validated in a literature review in 2017, where the patient-centeredness outcomes of BR in the setting of post-mastectomy radiotherapy were recorded, as it consolidated the available data regarding three main outcomes, which can facilitate the informed consent and SDM process of BR in the setting of post-mastectomy radiotherapy, including aesthetic effect, patient satisfaction and the BREAST-Q. ${ }^{18}$

Third, in view of the common phenomenon of the conflation of the SDM process and the use of PDAs, there is always a narrow focus on the SDM outcomes, which is not only for BR patients. Previous SRs have highlighted the effectiveness of decision aids for improving patient outcomes. ${ }^{11}$ There appeared to be a belief that tools designed to deliver information to patients could lead patients and clinicians to engage in a process of collaboration and deliberation. In fact, that is not the case. In terms of the association between SDM and patient outcomes, several authors have revealed that communication between healthcare professionals and patients, including SDM processes, can both directly and indirectly improve health outcomes. ${ }^{111}$

The empirical evidence surrounding SDM is not merely confined to studies of decision aids. According to different designs of SDM, the outcome index of patients participating can be divided into numerous aspects, which can refer to the results in our study about the outcome indicators measuring the degree of perceived participation in decision-making. This includes Modified-Perceived Involvement in Care Scale (M-PICS), CollaboRATE (a 3-item self-report measure of the patient experience of SDM process), Involvement in the BR decision-making process scale, and Shared Decision Making Questionnaire (SDM-Q-9). By evaluating the participation of patients in the process of SDM, and the behavior of healthcare professionals, we can clarify the weaknesses of healthcare professionals in the implementation of SDM and subsequently improve it. In hopes to promote the clinical practice of SDM.

Fourth, the results of this study show that there is insufficient attention to cost regarding $\mathrm{BC}$ patients with BR in SDM-related research. A Cochrane SR on PDAs also suggests further studies into costs. ${ }^{112}$ Future research should describe the hourly cost of SDM and the cost involved in developing PDAs, and consider cost-effectiveness as an important outcome measurement.

To date, SDM outcomes have typically been focused on short-term outcomes like patient's cognitive and affective outcomes. ${ }^{112,113}$ Also, SDM has almost always been measured cross-sectionally in the context of one interaction or discussion, which may not lead to improved health outcomes. Instead, a long-standing relationship between a clinician and patient influenced by SDM may impact outcomes over time. From the patient's point of view, SDM may improve patient satisfaction, which may lead to trust in the physician over time, followed by adherence to physician recommendations and ultimately improved health. ${ }^{114}$ From the perspective of the clinician, the SDM process could be viewed as either intrinsically rewarding and protective, or burdensome and impractical. However, studies have paid insufficient attention to the impact on professionals, whether those are either positive or negative. ${ }^{115}$ Therefore, we believe that well-designed studies are needed to that measure multiple patient and physician interactions, and patient outcomes over time, to formally test whether it is these increases in SDM that are associated with improved health outcomes.

\section{Strengths and Limitations}

This study has ambitious goals. This team looks forward to mapping the concerns of all relevant studies in the whole BR SDM field, and to summarizing all topics related to BR SDM. Since we extracted the information that can answer our research questions no matter it appeared in the method, results, discussion, or other sections, the expression used in presenting the results for this study was "many studies focus on" rather than "many studies' results are". This also shows that our analysis can only describe the current research focus and provide direction to future systematic reviews, but not be directly used as evidence for practice. However, for a young research field, 
we consider this broad scoping review to be an important first step in obtaining an overview of this topic.

A second limitation is that the search was limited to only 9 accessible electronic databases, so we may have missed relevant publications. However, we prioritized sensitivity in our electronic search, which was reflected in the extensive screening of abstracts to identify the most relevant work. In addition, we conducted an extensive gray literature search. Another limitation is that we did not perform a double assessment and double data extraction of the entire literature. However, whenever there was a slight doubt, we consulted a second reviewer to minimize errors. A major strength of this review is that it is the first review to focus solely on SDM for $\mathrm{BR}$ in BC patients. In previous work, the focus has been mainly on the interventional tool level, and the larger concept has not been studied in depth.

\section{Conclusion}

Although researchers have paid less attention to other research points in the field of SDM, compared to the design and application of SDM interventional tools, this research team still presents some equally noteworthy points through scoping review. For instance, the various factors influencing BC patients' participation in SDM for $\mathrm{BR}$ (especially at the healthcare provider level and at the organizational system level), including patients' experiences and perceptions. SRs should be conducted to quantify the impact of these different factors on BR SDM. Implementation of scientific theories and methods can inform the exploration and integration of these factors.

\section{Abbreviations}

$\mathrm{BC}$, breast cancer; BR, breast reconstruction; SDM, shared decision-making; ODSF, Ottawa Decision Support Framework; PDAs, Patients' decisional aids; IARC, International Agency for Research on Cancer; EUSOMA, European Society of BC Specialists; SRs, systematic reviews; SR, systematic review; RCTs, randomized controlled trials; PRISMA-ScR, Preferred Reporting Items for Systematic reviews and Meta-Analysis extension for Scoping Reviews; PCC, populations, concepts; IPDAS, International Patient Decision Aids Standards.

\section{Ethics Approval and Consent to Participate}

Since the scoping review methodology consists of reviewing and synthesizing already published data, this part of the study is not subject to ethical approval. Ethical approval and informed consent will be obtained prior to the consultation stage.

\section{Acknowledgments}

This paper was supported by University-level Key Research Project of Beijing University of Chinese Medicine (project level) (Grant Number 2020-JYBZDGG-075). The funders are not involved in the study design, data collection and analysis, manuscript writing or the decision to submit the manuscript for publication.

\section{Author Contributions}

All authors made a significant contribution to the work reported, whether that is in the conception, study design, execution, acquisition of data, analysis and interpretation, or in all these areas; took part in drafting, revising or critically reviewing the article; gave final approval of the version to be published; have agreed on the journal to which the article has been submitted; and agree to be accountable for all aspects of the work.

\section{Disclosure}

The authors report no conflicts of interest in this work.

\section{References}

1. World Cancer Day: Breast cancer overtakes lung cancer in terms of number of new cancer cases worldwide. IARC showcases key research projects to address breast cancer; 2021. Available from: https://www.iarc.who.int/ news-events/world-cancer-day-2021/. Accessed February 1, 2021.

2. Global cancer observatory: cancer today. Lyon, France: International Agency for Research on Cancer; 2020. Available from: https://gco. iarc.fr/today. Accessed February 1, 2021.

3. Watkins EJ. Overview of breast cancer. JAAPA. 2019;32(10):13-17. doi:10.1097/01.JAA.0000580524.95733.3d

4. Houssami N, Turner RM, Morrow M. Meta-analysis of pre-operative magnetic resonance imaging (MRI) and surgical treatment for breast cancer. Breast Cancer Res Treat. 2017;165(2):273-283. doi:10.1007/ s10549-017-4324-3

5. Unukovych D, Johansson H, Brandberg Y. Preoperative psychosocial characteristics may predict body image and sexuality two years after risk-reducing mastectomy: a prospective study. Gland Surg. 2017;6 (1):64-72. doi:10.21037/gs.2017.01.04

6. Latifi M, Salimi S, Barahmand N, Fahimnia F, Allahbakhshian Farsani L. Postmastectomy information needs and information-seeking motives for women with breast cancer. Adv Biomed Res. 2018;7:75. doi:10.4103/abr.abr_187_17

7. Figueiredo MI, Cullen J, Hwang YT, Rowland JH, Mandelblatt JS. Breast cancer treatment in older women: does getting what you want improve your long-term body image and mental health? J Clin Oncol. 2004;22(19):4002-4009. doi:10.1200/JCO.2004.07.030

8. Campbell-Enns H, Woodgate R. The psychosocial experiences of women with breast cancer across the lifespan: a systematic review protocol. JBI Database System Rev Implement Rep. 2015;13(1):112121. doi:10.11124/jbisrir-2015-1795 
9. McNeely ML, Binkley JM, Pusic AL, Campbell KL, Gabram S, Soballe PW. A prospective model of care for breast cancer rehabilitation: postoperative and postreconstructive issues. Cancer. 2012;118(8 Suppl):2226-2236. doi:10.1002/cncr.27468

10. Danino MA, Giaccone D, El Khatib A, et al. Immediate breast reconstruction surgery with expander/direct implant and use of acellular dermal matrix: does hormone therapy increases the risk of infection? Ann Chir Plast Esthet. 2020;65(4):277-283. doi:10.1016/j.anplas.2020.03.001

11. Berlin NL, Tandon VJ, Hawley ST, et al. Feasibility and efficacy of decision aids to improve decision making for postmastectomy breast reconstruction: a systematic review and meta-analysis. Med Decis Making. 2019;39(1):5-20. doi:10.1177/0272989X18803879

12. Paraskeva N, Guest E, Lewis-Smith H, Harcourt D. Assessing the effectiveness of interventions to support patient decision making about breast reconstruction: a systematic review. Breast. 2018;40:97-105. doi:10.1016/j.breast.2018.04.020

13. McQuirter M, Castiglia LL, Loiselle CG, Wong N. Decisionmaking process of women carrying a BRCA1 or BRCA2 mutation who have chosen prophylactic mastectomy. Oncol Nurs Forum. 2010;37(3):313-320. doi:10.1188/10.ONF.313-320

14. Myckatyn TM, Parikh RP, Lee C, Politi MC. Challenges and solutions for the implementation of shared decision-making in breast reconstruction. Plast Reconstr Surg Glob Open. 2020;8 (2):e2645. doi:10.1097/GOX.0000000000002645

15. Lamore K, Flahault C, Untas A. Women and partners' information need, emotional adjustment, and breast reconstruction decision-making before mastectomy. Plast Surg (Oakv). 2020;28 (3):179-188. doi:10.1177/2292550320928558

16. Santosa KB, Qi J, Kim HM, Hamill JB, Wilkins EG, Pusic AL. Long-term patient-reported outcomes in postmastectomy breast reconstruction. JAMA Surg. 2018;153(10):891-899. doi:10.1001/ jamasurg.2018.1677

17. Fortunato L, Loreti A, Cortese G, et al. Regret and quality of life after mastectomy with or without reconstruction. Clin Breast Cancer. 2020;S1526-8209(19)30736-0. doi:10.1016/j. clbc.2019.11.005

18. El-Sabawi B, Ho AL, Sosin M, Patel KM. Patient-centered outcomes of breast reconstruction in the setting of post-mastectomy radiotherapy: a comprehensive review of the literature. $J$ Plast Reconstr Aesthet Surg. 2017;70(6):768-780. doi:10.1016/j. bjps.2017.02.015

19. Ng SK, Hare RM, Kuang RJ, Smith KM, Brown BJ, HunterSmith DJ. Breast reconstruction post mastectomy: patient satisfaction and decision making. Ann Plast Surg. 2016;76(6):640644. doi:10.1097/SAP.0000000000000242

20. Elwyn G, Frosch D, Thomson R, et al. Shared decision making: a model for clinical practice. J Gen Intern Med. 2012;27(10):13611367. doi:10.1007/s11606-012-2077-6

21. Elwyn G, Frosch DL, Kobrin S. Implementing shared decisionmaking: consider all the consequences. Implement Sci. 2016;11:114. doi:10.1186/s13012-016-0480-9

22. Truglio-Londrigan M, Slyer JT. Shared decision-making for nursing practice: an integrative review. Open Nurs J. 2018;12:1-14. doi:10.2174/1874434601812010001

23. Beers E, Lee Nilsen M, Johnson JT. The role of patients: shared decision-making. Otolaryngol Clin North Am. 2017;50(4):689708. doi:10.1016/j.otc.2017.03.006

24. Lee BT, Agarwal JP, Ascherman JA, et al. Evidence-based clinical practice guideline: autologous breast reconstruction with DIEP or pedicled TRAM abdominal flaps. Plast Reconstr Surg. 2017;140(5):651e-664e. doi:10.1097/PRS.0000000000003768

25. Inokuchi M, Kutomi G, Kijima Y, et al. The Japanese Breast Cancer Society clinical practice guidelines for surgical treatment of breast cancer. Breast Cancer. 2020;27(1):4-8. doi:10.1007/ s12282-019-01030-w
26. Hendriks MP, Verbeek XAAM, van Manen JG, et al. Clinical decision trees support systematic evaluation of multidisciplinary team recommendations. Breast Cancer Res Treat. 2020;183 (2):355-363. doi:10.1007/s10549-020-05769-1

27. Biganzoli L, Cardoso F, Beishon $\mathrm{M}$, et al. The requirements of a specialist breast centre. Breast. 2020;51:65-84. doi:10.1016/j. breast.2020.02.003

28. Hamnett KE, Subramanian A. Breast reconstruction in older patients: a literature review of the decision-making process. $J$ Plast Reconstr Aesthet Surg. 2016;69(10):1325-1334. doi:10.1016/j.bjps.2016.06.003

29. Boateng J, Lee CN, Foraker RE, et al. Implementing an electronic clinical decision support tool into routine care: a qualitative study of stakeholders' perceptions of a post-mastectomy breast reconstruction tool. MDM Policy Pract. 2021;6 (2):23814683211042010. doi:10.1177/23814683211042010

30. Grabinski VF, Myckatyn TM, Lee CN, Philpott-Streiff SE, Politi MC. Importance of shared decision-making for vulnerable populations: examples from postmastectomy breast reconstruction. Health Equity. 2018;2:234-238. doi:10.1089/heq.2018.0020

31. Ogrodnik A, MacLennan S, Weaver D, James T. Barriers to completing delayed breast reconstruction following mastectomy: a critical need for patient and clinician education. J Cancer Educ. 2017;32(4):700-706. doi:10.1007/s13187-016-1046-x

32. Pham MT, Rajić A, Greig JD, Sargeant JM, Papadopoulos A, McEwen SA. A scoping review of scoping reviews: advancing the approach and enhancing the consistency. Res Synth Methods. 2014;5(4):371-385. doi:10.1002/jrsm.1123

33. Daudt HM, van Mossel C, Scott SJ. Enhancing the scoping study methodology: a large, inter-professional team's experience with Arksey and O'Malley's framework. BMC Med Res Methodol. 2013;13:48. doi:10.1186/1471-2288-13-48

34. Arksey H, O'Malley L. Scoping studies: towards a methodological framework. Int $J$ Soc Res Methodol. 2005;8:19-32. doi:10.1080/136455703200-0119616

35. Moher D, Liberati A, Tetzlaff J, Dg A, The PRISMA Group. Preferred reporting items for systematic reviews and meta-analyses: the PRISMA statement. PLoS Med. 2009;6(7):e1000097. doi:10.1371/journal.pmed.1000097

36. Meng M. Analysis of the current situation of shared decisionmaking in breast reconstruction for breast cancer: a scoping review protocol.

37. The Joanna Briggs Institute. Joanna Briggs Institute Reviewers' Manual: 2015 edition/Supplement. Australia: The Joanna Briggs Institute; 2015.

38. Stacey D, Légaré F, Boland L, et al. 20th anniversary Ottawa decision support framework: part 3 overview of systematic reviews and updated framework. Med Decis Making. 2020;40 (3):379-398. doi:10.1177/0272989X20911870

39. Vaismoradi M, Turunen H, Bondas T. Content analysis and thematic analysis: implications for conducting a qualitative descriptive study. Nurs Health Sci. 2013;15(3):398-405. doi:10.1111/ nhs. 12048

40. Sherman KA, Harcourt DM, Lam TC, Shaw LK, Boyages J. BRECONDA: development and acceptability of an interactive decisional support tool for women considering breast reconstruction. Psychooncology. 2014;23(7):835-838. doi:10.1002/ pon.3498

41. Sherman KA, Shaw LE, Winch CJ, et al., BRECONDA Collaborative Research Group. Reducing decisional conflict and enhancing satisfaction with information among women considering breast reconstruction following mastectomy: results from the BRECONDA Randomized Controlled Trial. Plast Reconstr Surg. 2016;138(4):592e-602e. doi:10.1097/ PRS.0000000000002538 
42. Sherman KA, Shaw LK, Jørgensen L, et al. Qualitatively understanding patients' and health professionals' experiences of the BRECONDA breast reconstruction decision aid. Psychooncology. 2017;26(10):1618-1624. doi:10.1002/pon.4346

43. Parkinson B, Sherman KA, Brown P, et al. Cost-effectiveness of the BRECONDA decision aid for women with breast cancer: results from a randomized controlled trial. Psychooncology. 2018;27(6):1589-1596. doi:10.1002/pon.4698

44. Tollow P, Paraskeva N, Clarke A, et al. 'They were aware of who I was as a person': patients' and health professionals' experiences of using the PEGASUS intervention to facilitate decision-making around breast reconstruction. Eur J Cancer Care (Engl). 2021;30: e13464. doi:10.1111/ecc.13464

45. Clarke A, Paraskeva N, White P, Tollow P, Hansen E, Harcourt D. PEGASUS: the design of an intervention to facilitate shared decision-making in breast reconstruction. $J$ Cancer Educ. 2021;36(3):508-518. doi:10.1007/s13187-019-01656-6

46. Harcourt D, Paraskeva N, White P, Powell J, Clarke A. A study protocol of the effectiveness of PEGASUS: a multi-centred study comparing an intervention to promote shared decision making about breast reconstruction with treatment as usual. BMC Med Inform Decis Mak. 2017;17(1):143. doi:10.1186/s12911-017-0543-0

47. Manne SL, Topham N, D'Agostino TA, et al. Acceptability and pilot efficacy trial of a web-based breast reconstruction decision support aid for women considering mastectomy. Psychooncology. 2016;25(12):1424-1433. doi:10.1002/pon.3984

48. Yan W, Liyuan S, Jingyue Z. Analysis of decision status and influencing factors of patients after breast cancer. $J$ Nurse Stud. 2019;34(13):1225-1227.

49. Frisell A, Lagergren J, de Boniface J. National study of the impact of patient information and involvement in decision-making on immediate breast reconstruction rates. Br J Surg. 2016;103 (12):1640-1648. doi:10.1002/bjs.10286

50. Elmore L, Myckatyn TM, Gao F, et al. Reconstruction patterns in a single institution cohort of women undergoing mastectomy for breast cancer. Ann Surg Oncol. 2012;19(10):3223-3229. doi:10.1245/s10434-012-2530-0

51. Lee CN, Belkora J, Chang Y, Moy B, Partridge A, Sepucha K. Are patients making high-quality decisions about breast reconstruction after mastectomy? [outcomes article]. Plast Reconstr Surg. 2011;127(1):18-26. doi:10.1097/PRS.0b013e3181f958de

52. de Ligt KM, van Bommel ACM, Schreuder K, et al., NABON Breast Cancer Audit Working Group. The effect of being informed on receiving immediate breast reconstruction in breast cancer patients. Eur J Surg Oncol. 2018;44(5):717-724. doi:10.1016/j.ejso.2018.01.226

53. Naiyuan T. Multienter Study on Breast Reconstruction and Impact Factors in Breast Cancer Patients [dissertation]. Peking Union Medical College; 2018.

54. Nelson JA, Fischer JP, Radecki MA, et al. Delayed autologous breast reconstruction: factors which influence patient decision making. J Plast Reconstr Aesthet Surg. 2013;66(11):1513-1520. doi:10.1016/j.bjps.2013.06.020

55. Begum S, Grunfeld EA, Ho-Asjoe M, Farhadi J. An exploration of patient decision-making for autologous breast reconstructive surgery following a mastectomy. Patient Educ Couns. 2011;84 (1):105-110. doi:10.1016/j.pec.2010.07.004

56. Flitcroft K, Brennan M, Costa D, Wong A, Snook K, Spillane A. An evaluation of factors affecting preference for immediate, delayed or no breast reconstruction in women with high-risk breast cancer. Psychooncology. 2016;25(12):1463-1469. doi:10.1002/pon.4087
57. Temple-Oberle C, Ayeni O, Webb C, Bettger-Hahn M, Ayeni O, Mychailyshyn N. Shared decision-making: applying a personcentered approach to tailored breast reconstruction information provides high satisfaction across a variety of breast reconstruction options. J Surg Oncol. 2014;110(7):796-800. doi:10.1002/ jso. 23721

58. Hui KJ, Liu XX, Luan A, Lee GK. Design and focus test of a preconsultation decision aid for breast cancer reconstruction patients: a quality improvement initiative. Eplasty. 2015;15:e24.

59. López M, Inmaculada DM-F, Rodríguez A, Muñoz M. Reconstrucción inmediata en cÁncer de mama. ¿las mujeres estÁn satisfechas con su decisión? Psicooncología. 2015;12 (2):393-403. doi:10.5209/rev PSIC.2015.v12.n2-3.51017

60. Lee CN, Hultman CS, Sepucha K. What are patients' goals and concerns about breast reconstruction after mastectomy? Ann Plast Surg. 2010;64(5):567-569. doi:10.1097/SAP.0b013e3181bffc9b

61. Kuo NT, Kuo YL, Lai HW, Ko NY, Fang SY. The influence of partner involvement in the decision-making process on body image and decision regret among women receiving breast reconstruction. Support Care Cancer. 2019;27(5):1721-1728. doi:10.1007/s00520-018-4416-6

62. Nelson JA, Tchou J, Domchek S, Sonnad SS, Serletti JM, Wu LC. Breast reconstruction in bilateral prophylactic mastectomy patients: factors that influence decision making. $J$ Plast Reconstr Aesthet Surg. 2012;65(11):1481-1489. doi:10.1016/j. bjps.2012.05.001

63. Hasak JM, Myckatyn TM, Grabinski VF, Philpott SE, Parikh RP, Politi MC. Stakeholders' perspectives on postmastectomy breast reconstruction: recognizing ways to improve shared decision making. Plast Reconstr Surg Glob Open. 2017;5(11):e1569. doi:10.1097/GOX.0000000000001569

64. Lee CN, Hultman CS, Sepucha K. Do patients and providers agree about the most important facts and goals for breast reconstruction decisions? Ann Plast Surg. 2010;64(5):563-566. doi:10.1097/SAP.0b013e3181c01279

65. Lamore K, Flahault C, Fasse L, Untas A. Waiting for breast reconstruction": an interpretative phenomenological analysis of heterosexual couples' experiences of mastectomy for breast cancer. Eur J Oncol Nurs. 2019;42:42-49. doi:10.1016/j. ejon.2019.07.008

66. Causarano N, Platt J, Baxter NN, et al. Pre-consultation educational group intervention to improve shared decision-making for postmastectomy breast reconstruction: a pilot randomized controlled trial. Support Care Cancer. 2015;23(5):1365-1375. doi:10.1007/s00520-014-2479-6

67. Hoffman AS, Cantor SB, Fingeret MC, et al. Considering breast reconstruction after mastectomy: a patient decision aid video and workbook. Plast Reconstr Surg Glob Open. 2019;7(11):e2500. doi:10.1097/GOX.0000000000002500

68. Potter S, Mills N, Cawthorn S, Wilson S, Blazeby J. Exploring inequalities in access to care and the provision of choice to women seeking breast reconstruction surgery: a qualitative study. Br J Cancer. 2013;109(5):1181-1191. doi:10.1038/ bjc. 2013.461

69. Carr TL, Groot G, Cochran D, Vancoughnett M, Holtslander L. Exploring women's support needs after breast reconstruction surgery: a Qualitative Study. Cancer Nurs. 2019;42(2):E1-E9. doi:10.1097/NCC.0000000000000600

70. Lin PJ, Fang SY, Kuo YL. Development and usability testing of a decision support app for women considering breast reconstruction surgery. J Cancer Educ. 2021;36(1):160-167. doi:10.1007/ s13187-019-01612-4 
71. Yan ZW, Xiaoyuan W, Liyuan S, et al. Construction and application of decision assistance for patients with breast breast reconstruction surgery. Chin Nurs J. 2020;55(01):90-95.

72. Politi MC, Lee CN, Philpott-Streiff SE, et al. A randomized controlled trial evaluating the BREASTChoice tool for personalized decision support about breast reconstruction after mastectomy. Ann Surg. 2020;271(2):230-237. doi:10.1097/SLA.0000000000003444

73. Ter Stege JA, Woerdeman LAE, Hahn DEE, et al. The impact of an online patient decision aid for women with breast cancer considering immediate breast reconstruction: study protocol of a multicenter randomized controlled trial. BMC Med Inform Decis Mak. 2019;19(1):165. doi:10.1186/s12911-019-0873-1

74. Sherman KA, Kilby CJ, Shaw LK, et al. Facilitating decisionmaking in women undergoing genetic testing for hereditary breast cancer: BRECONDA randomized controlled trial results. Breast. 2017;36:79-85. doi:10.1016/j.breast.2017.10.001

75. Platt J, Baxter N, Jones J, et al. Pre-consultation educational group intervention to improve shared decision-making in postmastectomy breast reconstruction: study protocol for a pilot randomized controlled trial. Trials. 2013;14:199. doi:10.1186/17456215-14-199

76. Lam WW, Chan M, Or A, Kwong A, Suen D, Fielding R. Reducing treatment decision conflict difficulties in breast cancer surgery: a randomized controlled trial. J Clin Oncol. 2013;31 (23):2879-2885. doi:10.1200/JCO.2012.45.1856

77. Ashraf AA, Colakoglu S, Nguyen JT, et al. Patient involvement in the decision-making process improves satisfaction and quality of life in postmastectomy breast reconstruction. J Surg Res. 2013;184(1):665-670. doi:10.1016/j.jss.2013.04.057

78. Ananian P, Houvenaeghel G, Protière C, et al. Determinants of patients' choice of reconstruction with mastectomy for primary breast cancer. Ann Surg Oncol. 2004;11(8):762-771. doi:10.1245/ ASO.2004.11.027

79. Au AH, Lam WW, Chan MC, et al. Development and pilottesting of a Decision Aid for use among Chinese women facing breast cancer surgery. Health Expect. 2011;14(4):405-416. doi:10.1111/j.1369-7625.2010.00655.x

80. Lam A, Secord S, Butler K, et al. A breast reconstruction needs assessment: how does self-efficacy affect information access and preferences? Can J Plast Surg. 2012;20(1):37-42. doi:10.1177/ 229255031202000101

81. Heller L, Parker PA, Youssef A, Miller MJ. Interactive digital education aid in breast reconstruction. Plast Reconstr Surg. 2008;122(3):717-724. doi:10.1097/PRS.0b013e318180ed06

82. Zisman-Ilani Y, Obeidat R, Fang L, Hsieh S, Berger Z. Shared decision making and patient-centered care in Israel, Jordan, and the United States: exploratory and comparative survey study of physician perceptions. JMIR Form Res. 2020;4(8):e18223. doi: $10.2196 / 18223$

83. Metcalfe K, Zhong T, O’Neill AC, et al. Development and testing of a decision aid for women considering delayed breast reconstruction. J Plastic, Reconstructive Aesthetic Surg. 2018;71 (3):318-326. doi:10.1016/j.bjps.2017.08.027

84. Manne SL, Topham N, D'Agostino TA, et al. Acceptability and pilot efficacy trial of a web-based breast reconstruction decision support aid for women considering mastectomy. Psychooncology. 2016;25(12):1424-1433. doi:10.1002/pon.3984

85. Cavazos-Rehg PA, Fitzsimmons-Craft EE, Krauss MJ, et al. Examining the self-reported advantages and disadvantages of socially networking about body image and eating disorders. Int $J$ Eat Disord. 2020;53(6):852-863. doi:10.1002/eat.23282

86. Passow S, Thurm F, Li SC. Activating developmental reserve capacity via cognitive training or non-invasive brain stimulation: potentials for promoting fronto-parietal and hippocampal-striatal network functions in old age. Front Aging Neurosci. 2017;9:33. doi:10.3389/fnagi.2017.00033
87. Málaga G, Romero ZO, Málaga AS, Cuba-Fuentes S. Shared decision making and the promise of a respectful and equitable healthcare system in Peru. Z Evid Fortbild Qual Gesundhwes. 2017;123-124:81-84. doi:10.1016/j.zefq.2017.05.021

88. Isselhard A, Töpper M, Berger-Höger B, et al. Implementation and evaluation of a nurse-led decision-coaching program for healthy breast cancer susceptibility gene (BRCA1/2) mutation carriers: a study protocol for the randomized controlled EDCP-BRCA study. Trials. 2020;21(1):501. doi:10.1186/s13063-020-04431-X

89. Boland L, Graham ID, Légaré F, et al. Barriers and facilitators of pediatric shared decision-making: a systematic review. IS. 2019;14(1):7. doi:10.1186/s13012-018-0851-5

90. Covvey JR, Kamal KM, Gorse EE, et al. Barriers and facilitators to shared decision-making in oncology: a systematic review of the literature. Support Care Cancer. 2019;27(5):1613-1637. doi:10.1007/s00520-019-04675-7

91. O’Donnell A, Buffo A, Campbell TC, Ehlenbach WJ. The critical care nurse communicator program: an integrated primary palliative care intervention. Crit Care Nurs Clin North Am. 2020;32 (2):265-279. doi:10.1016/j.cnc.2020.02.008

92. Allaby MA, Chrisp P. NICE supports shared decision making. BMJ. 2019;364:11038. doi:10.1136/bmj.11038

93. Nealon KP, Weitzman RE, Sobti N, et al. Prepectoral direct-toimplant breast reconstruction: safety outcome endpoints and delineation of risk factors. Plast Reconstr Surg. 2020;145(5):898e908e. doi:10.1097/PRS.0000000000006721

94. Sada A, Day CN, Hoskin TL, Degnim AC, Habermann EB, Hieken TJ. Mastectomy and immediate breast reconstruction in the elderly: trends and outcomes. Surgery. 2019;166(4):709-714. doi:10.1016/j.surg.2019.05.055

95. Ozturk C, Ozturk CN, Platek M, et al. Management of expander- and implant-associated infections in breast reconstruction. Aesthetic Plast Surg. 2020;44(6):2075-2082. doi:10.1007/s00266-020-01923-8

96. Ricci JA, Epstein S, Momoh AO, Lin SJ, Singhal D, Lee BT. A meta-analysis of implant-based breast reconstruction and timing of adjuvant radiation therapy. J Surg Res. 2017;218:108-116. doi:10.1016/j.jss.2017.05.072

97. Schmidt JL, Wetzel CM, Lange KW, Heine N, Ortmann O. Patients' experience of breast reconstruction after mastectomy and its influence on postoperative satisfaction. Arch Gynecol Obstet. 2017;296(4):827-834. doi:10.1007/s00404-017-4495-5

98. Fallbjörk U, Rasmussen BH, Karlsson S, Salander P. Aspects of body image after mastectomy due to breast cancer - A two-year follow-up study. Eur J Oncol Nurs. 2013;17(3):340-345. doi:10.1016/j.ejon.2012.09.002

99. Lee CN, Pignone MP, Deal AM, et al. Accuracy of predictions of patients with breast cancer of future well-being after immediate breast reconstruction. JAMA Surg. 2018;153(4):e176112. doi:10.1001/jamasurg.2017.6112

100. Scholl I, LaRussa A, Hahlweg P, Kobrin S, Elwyn G. Organizational- and system-level characteristics that influence implementation of shared decision-making and strategies to address them - A scoping review. IS. 2018;13(1):40. doi:10.1186/s13012-018-0731-z

101. Kew KM, Malik P, Aniruddhan K, Normansell R. Shared decision-making for people with asthma. Cochrane Database Syst Rev. 2017;10(10):CD012330. doi:10.1002/14651858.CD012330. pub2

102. Fisher A, Mills K, Teesson M, Marel C. Shared decision-making among people with problematic alcohol/other drug use and cooccurring mental health conditions: a systematic review. Drug Alcohol Rev. 2021;40(2):307-324. doi:10.1111/dar.13149

103. Fukunaga MI, Halligan K, Kodela J, et al. Tools to promote shared decision-making in lung cancer screening using low-dose CT scanning: a systematic review. Chest. 2020;158(6):26462657. doi:10.1016/j.chest.2020.05.610 
104. Doherty AJ, Boland P, Reed J, et al. Barriers and facilitators to deprescribing in primary care: a systematic review. BJGP Open 2020;4(3):bjgpopen20X101096. doi:10.3399/bjgpopen20X101096

105. Horey D, Kealy M, Davey MA, Small R, Crowther CA. Interventions for supporting pregnant women's decision-making about mode of birth after a caesarean. Cochrane Database Syst Rev. 2013;7:CD010041.

106. Elwyn G, Frosch DL, Kobrin S. Implementing shared decisionmaking: consider all the consequences. Implement Sci. 2015;11 (1). doi:10.1186/s13012-016-0480-9

107. Hargraves I, LeBlanc A, Shah ND, Montori VM. Shared decision making: the need for patient-clinician conversation, not just information. Health Affair. 2016;35(4):627-629. doi:10.1377/ hlthaff.2015.1354

108. Elwyn G, O'Connor A, Stacey D, et al. Developing a quality criteria framework for patient decision aids: online international Delphi consensus process. BMJ. 2006;333(7565):417. doi:10.1136/bmj.38926.629329.AE

109. Niburski K, Guadagno E, Mohtashami S, Poenaru D. Shared decision making in surgery: a scoping review of the literature. Health Expect. 2020;23(5):1241-1249. doi:10.1111/hex.13105

110. Berlin NL, Tandon VJ, Hawley ST, et al. Feasibility and efficacy of decision aids to improve decision making for postmastectomy breast reconstruction: a systematic review and meta-analysis. Med Decis Making. 2019;39(1):5-20. doi:10.1177/0272989X18803879
111. Tulsky JA, Beach MC, Butow PN, et al. A research agenda for communication between health care professionals and patients living with serious illness. JAMA Intern Med. 2017;177 (9):1361-1366. doi:10.1001/jamainternmed.2017.2005

112. Stacey D, Légaré F, Lewis $\mathrm{K}$, et al. Decision aids for people facing health treatment or screening decisions. Cochrane Database Syst Rev. 2017;4(4):CD001431. doi:10.1002/ 14651858.CD001431.pub5

113. Hoefel L, Lewis KB, O’Connor A, Stacey D. 20th anniversary update of the Ottawa decision support framework: part 2 subanalysis of a systematic review of patient decision aids. Med Decis Making. 2020;40(4):522-539. doi:10.1177/0272989X20924645

114. Lafata JE, Morris HL, Dobie E, Heisler M, Werner RM, Dumenci L. Patient-reported use of collaborative goal setting and glycemic control among patients with diabetes. Patient Educ Couns. 2013;92(1):94-99. doi:10.1016/j.pec.2013.01.016

115. Légaré F, Adekpedjou R, Stacey D, et al. Interventions for increasing the use of shared decision making by healthcare professionals. Cochrane Database Syst Rev. 2018;7(7):CD006732. doi:10.1002/14651858.CD006732.pub4
Patient Preference and Adherence

\section{Publish your work in this journal}

Patient Preference and Adherence is an international, peer-reviewed, open access journal that focusing on the growing importance of patient preference and adherence throughout the therapeutic continuum. Patient satisfaction, acceptability, quality of life, compliance, persistence and their role in developing new therapeutic modalities and compounds to optimize clinical outcomes for existing disease states are major areas of interest for the journal. This journal has been accepted for indexing on PubMed Central. The manuscript management system is completely online and includes a very quick and fair peer-review system, which is all easy to use. Visit http:// www.dovepress.com/testimonials.php to read real quotes from published authors. 